\title{
DEVELOPMENT STRATEGY FOR MOBILE COMMUNICATIONS MARKET IN CHINESE RURAL AREA
}

\author{
Liwei Zhang ${ }^{1}$,Yanjun Zhang ${ }^{1}$, Liying $\mathrm{Xu}^{1}$, Daoliang $\mathrm{Li}^{1}{ }^{1, *}$ \\ ${ }^{1}$ College of Information and Electrical Engineering, China agricultural University, Beijing, \\ P. R. China, 100083 \\ * Corresponding author, Address: P. O. Box 121, College of Information and Electrical \\ Engineering, China Agricultural University, 17 Tsinghua East Road, Beijing, 100083, P. \\ R. China, Tel:+86-10-72737741,_Fax:+86-10-62737679,_Email: li_daoliang@yaohoo.com
}

Abstract: Based on full analysis of rural mobile communication market, in order to explore mobile operators in rural areas of information services for sustainable development model, this paper presents three different aspects, including rural mobile communications market demand, the rural market for mobile communications business model and development strategies for rural mobile communications market research business. It supplies some valuable references for operators to develop rural users rapidly, develop the rural market effectively and to get access to develop a broad space.

Keywords: Rural, Mobile Communications, Development Strategy

\section{INTRODUCTION}

China has a rural population of 737 million, accounting for $56 \%$ of the total Chinese population; More than 210,000,000 households, which accounted for 67.6 percent of total family, therefore, it is a huge potential consumer market. In other words, any communication product families as long as the rate increased by 1 percentage point, then it will increase more than 2,000,000 demands. If communication fee grows one yuan in each family, it will generate nearly 2 billion's communication needs. Evidently, compared to facing an increasingly saturated market of communication

Please use the following format when citing this chapter:

Zhang, L., Zhang, Y., Xu, L. and Li, D., 2009, in IFIP International Federation for Information Processing, Volume 295, Computer and Computing Technologies in Agriculture II, Volume 3, eds. D. Li, Z. Chunjiang, (Boston: Springer), pp. 1967-1975. 
difficulties in cities, the rural area is a very attractive large cake for telecom operators.( Jingyu Shi \& Jianqiu Zeng, 2007)

However, since farmers have weak awareness of informationization and low-level purchase, in order to bear the fruits of information technology on barren land, it needs a huge investment and long-term market foster. In that case, how will China's telecom operators to balance their own benefits and to open up rural information technology market?

According to analysis of the rural communications market, it is indicated that the primary reason of farmers using the communication tools is to facilitate the hope that rapid access to get useful information, be able to make the best of social and dynamic market for agricultural production and management services. Therefore in the progress of developing rural market, it is important for mobile operators to hold a tight grasp of the characteristics of rural communications to carry out the broad masses of the information service for farmers as a breakthrough point, so that farmers can get the communications tangible benefits, which spurs on mobile operators to occupy the rural market.(Jierong Guo,2006)

To explore sustainable development model for the rapid development of the rural operator customers, effectively in developing the rural market and get access to a broad the development of space for reference, this paper will analyze market analysis of the rural mobile telecommunications from the following three aspects: demand analysis, operation mode and development strategy.( Qifeng Gu \& Chengjie Yan, 2007)

\section{RURAL MOBILE COMMUNICATIONS MARKET DEMAND ANALYSIS}

Rural mobile user market can be divided into agriculture-related government work, agriculture-related enterprises, township cadres in village, township agricultural extension workers, agricultural marketing major, major processing of agricultural products breeding, farmers brokers, Common farmers, migrant workers and so on .( Qifeng Gu \& Chengjie Yan, 2007)

To develop the rural mobile telecommunications market in rural areas, it is first necessary to maximize the excavation of the main information needs, and then analyze the needs of the main requirements of the information needs of different groups of people have great differences.

(1) Major agricultural marketing, agricultural planting and processing large brokers

They are large brokers and business links with the outside world needs to understand the outside world, the mobile communications market in the rural areas of focus groups. The big brokers belonging to high-income groups in rural areas, communications and information services have a strong demand 
for highly value the development of the market. For such groups, whose main demand is to call, in general the number of calls, call for a long time and overhead charges greater demand for information are relatively large, charges and price adjustment on the role of the market segments are more obvious, they are the most potential users of mobile communications. These users belong to the rural market "customer" , mobile operators can refer to the city's large customer preferences and give appropriate incentives for rural areas, at the same time, doing SMS advertising business specific to some of the bosses, enabling them to become backbone of mobile communication services in rural income growth.

(2) Township and village cadres in the village of the township agricultural extension agents

This type of users have a relatively high education and relatively stable income, in the rural market, they are opinion leaders, seizing some of this kind of people as a development target, it means that the core of the rural market has been obtained. Such users are extremely sensitive to price, because of their higher level of education, relatively good price, the price, the price comparison is understood that all types of information are the main spreaders of the farmers have a greater influence. As a result, seizing this group in rural area is the key point to develop the rural market.

\section{(3) Agriculture-related government officials and agriculture-related business staff}

This type of users accounts for an absolute small population, but they are the largest source of customers for mobile communications company. In general leaders in government enterprises and institutions have a handset subsidy costs, the use of mobile phones is out of practical demand for work, they would not consider whether the cost of calls per month expenditure is much higher than average or not. Government civil servants in general have stable revenue, the expenditure on phone calls is also higher than average. In addition, due to the workers of the institutions have relatively high level of education, the value-added services and other services can be quickly accepted.

\section{(4) Common farmers}

They are the farmers specializing in agricultural production activities. These staff is characterized by low income, small mobility, less contact with the outside world; but the groups are in large scale, high-status at home, with the power to decide on the need to buy products, it is necessary to tap the market potential. The group stayed in rural areas (the family members of people working out), they are mainly women, children and elders having no direct revenue. However, compared to full-time farmers they have more stable consumer spending and stronger demand for communication.

\section{(5) Migrant workers}


It is primarily about local workers or other non-agricultural labor force work staff. They are township enterprises workers who are mainly young people with characteristic of following fashion, liking SMS new business volume, being more sensitive to price, these people belong to low consumer groups, but these large population has a relatively stable income, it is the major forces of rural cell phone numbers growth. It should be noted that: different working groups in the province of its location are mainly working and living in cities, they no longer belong to the rural market as the target group.

\section{RURAL MOBILE TELECOMMUNICATIONS MARKET BUSINESS MODEL}

The development process of the mobile communications market is mainly divided into three stages including communication services, information services and application services, corresponding to these three stages of market development, the business model in rural areas are basic mode of communication, information and services model and transaction service model.(Yan Wang \& Yufei Gao,2006)

\subsection{Basic mode of communication}

The basic mode of communication is consistent with business model in mobile operator's primary strategic form, the mode of the main mobile operators is located in mobile communications service provider, which is for users to provide access to information transmission, the provision of business service and more single to voice, point-to-point messaging service. It is shown in Figure1.

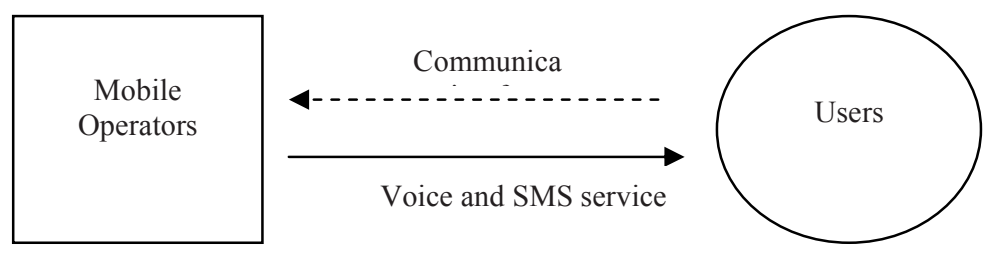

Figure1: Communication Mode

Mobile voice communication is a basic mode of communication of the most important business, the basic needs of mobile users, the first mobile communications and most common services. SMS is a telecommunications business accompanied with digital mobile communication system. In the early development of mobile communication, it is mainly used to achieve the 
communication between inter-network text messaging. Through the basic point-to-point voice and text messaging between mobile users, it can meet the communication needs of real-time information, point-to-point transmission.

In the rural areas, voice service is still the largest source of income, secondary to the voice messaging business is SMS, though in far less than the amount of voice service but it has a higher rate and will continue growing. The reasons for SMS business with low levels of certain major cities are mainly because in most parts of the users having low level of education and more lower-age young people working outside.

\subsection{Information service model}

Information service model is in the process of transacting from the mobile operators in the mobile communications service provider to the mobile information service provider, the formation of a new business model. Now thanks to the content and service providers' growing, the mobile operators are able to provide more rich mobile communications services, which are integrated by the content provider, transmit a large number of information through mobile operators to the hands of mobile users. It is shown in Figure2.

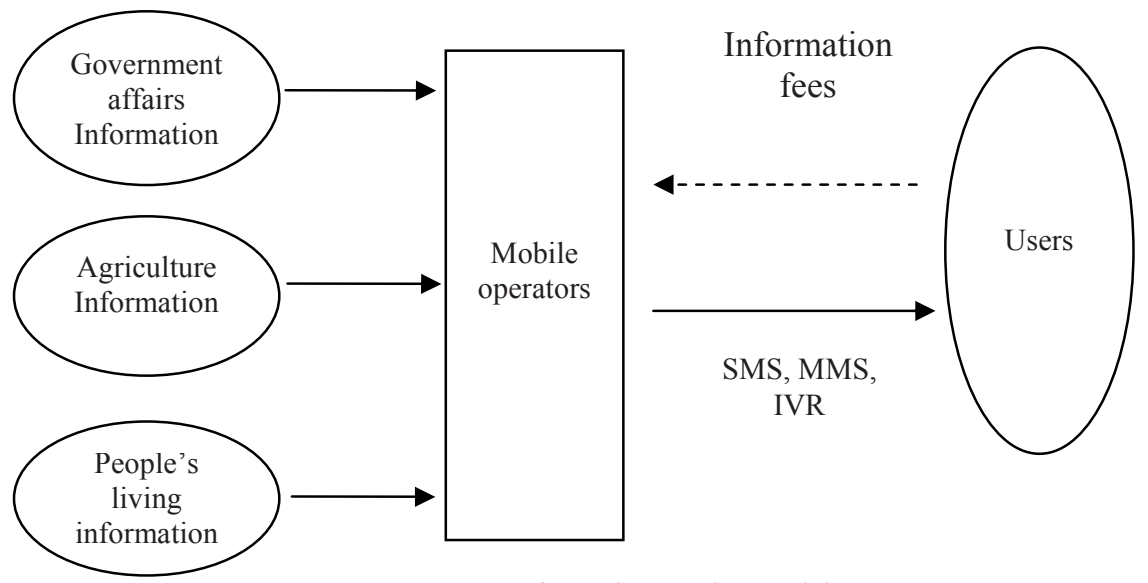

Figure2. Information service model

Custom SMS, MMS and IVR are the main modes of information services business. SMS Custom business refers to mobile phone users to customize Web site or on-demand by mobile operators to provide various types of short message service; MMS custom business, refers to mobile phone users, including customized web site or on-demand video and audio information, pictures, the contents of the text, such as multimedia messaging, text 
messaging and custom letter is relatively rich and varied content, the amount of information, but it need support MMS mobile phone services; IVR voice service means users dialing the designated number to obtain the necessary information or to participate in interactive services.

Information service model are widely used in the rural market, in the early period China Mobile launched the ICT, primarily by the way of text messages sent to the farmers, such as markets information and technology information, the following introduction of MMS products have been widely welcomed by users. Currently, IVR application in the rural market is in good condition, the voice of agricultural information service hotline is now available for users with automatic voice service, voice messaging services, voice services and artificial voice services.

\subsection{Transaction service model}

Referring to the main mode of transaction services means to complete transactions online and offline combination of services for customers, such as: trade intermediaries, agents, electronic payment, credit management and logistics services, which are named as depth of services. Mobile operators and application service providers cooperated with achieving customer service for both sides through mobile phon.It is shown in Figure3.

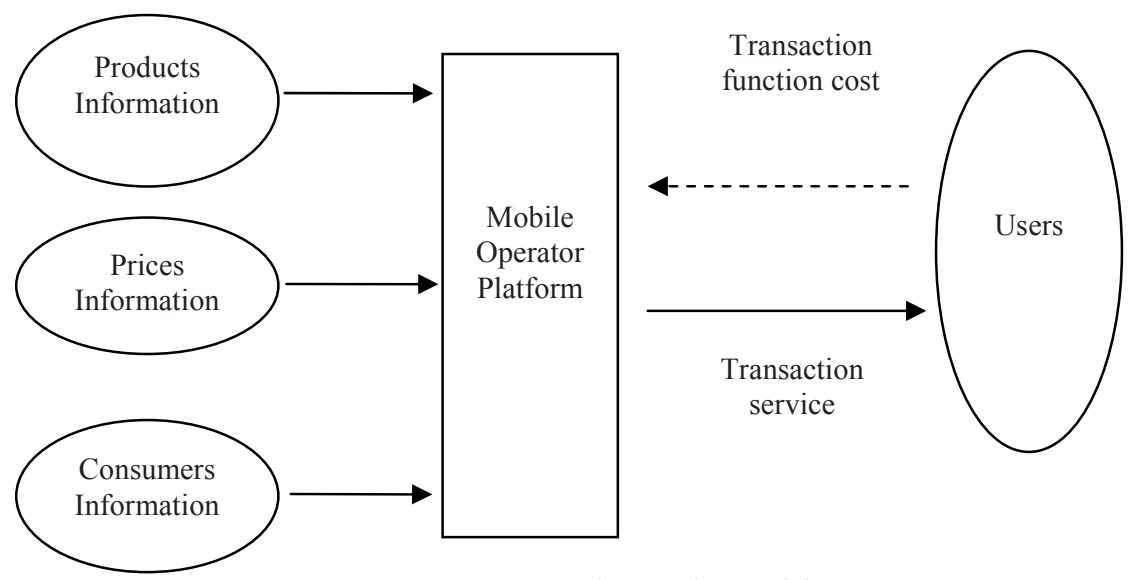

Figure3. Transaction service model

In view of the current situation in rural areas, it could classify information which are uploaded by sale customer by regions, variety, quantity and time of the transaction information, accurate information to trade matching, to solve the problem of difficulty in selling hard to buy; can also be set up agriculture-related supply and demand information exchange center The Center is currently available in addition to providing the functions of the 
Internet, the information provided by the transaction, you can enter text messages a central database, the information will first be sent to the user.

\section{RURAL MOBILE TELECOMMUNICATIONS MARKET DEVELOPMENT STRATEGY}

\subsection{Take carrying out rural information service as a breakthrough point to occupy the rural communications market rapidly}

After several years' rapid development, China's mobile market has exceeded 400,000,000 users, which become the world's largest market of users. In the growing number of the users, it is worth noting that, from the second half of 2003 to so far, the new low-end prepaid subscribers increased significantly, which means that China's mobile communication market is gradually moving the market to mature, high-end users The growth of stable, low-end users is the reason why the operator open up new users of the main objectives of the user base. With the mobile users in large and medium-sized cities gradually saturated market, it is foreseeable that the next few years, with a large number of low-end users of the 34 cities, towns and rural economic development, such as the extent of the region's poor, will be for new mobile users in the next major battlefield.

Due to China's rural communications market and the cities having their own characteristics including the pursuit of urban consumers personalized, fashion-oriented products and a variety of value-added services, rural consumers pay more attention to send and receive communications with voice and text messages and other basic functions, and practical information services, hoping that the purpose of communication is to facilitate rapid access to get useful information, which can be able to make the best social and dynamic market for agricultural production and management services, In order to develop the rural market mobile communications operators should grasp closely to the rural communications, which is a unique feature for the broad masses of farmers to carry out a service as a breakthrough point, so that farmers can get the communications tangible benefits, which will help them to occupy the rural market quickly. 


\subsection{For farmers' different spending power in different parts to implement different services strategy}

Because of different level of economic development, education and awareness of information in China's rural areas, there is a sense of a significant gap, resulting in different parts of the farmers having different purchasing power of information services, mobile communications operators should carry out information services according to different areas of information consumption level, which should be the implementation of differentiated service strategy.

1. For coastal and eastern suburbs of big cities with more developed economy, farmers have more spending power on information in these region, information services should rely mainly on market mechanisms, mobile operators should adopt the paid services strategy and improve the quality of information services and enhance information services benefits to attract customers at the core gradually open up the market.

2. For the areas with low level in economic development, farmers with limited spending power of information in the central grain-producing areas, information services should be free of charge lower fees and the road through the government sector, farm produce processing enterprises, agricultural businesses, such as the provision of information transmission platform for recovery of the agricultural information service The cost and the current focus on increasing awareness will expand services and improve their awareness of consumer information as well as the nurturing of rural communications markets.

3. For western region with underdeveloped economics, due to the low income of the farmers, who do not have a strong sense of the information, enabling them to spend money buying the information is not practical, to carry out the information services the mobile operators should provide free service, service costs as much as possible So that the supply of agricultural materials and agricultural products processing enterprises and develop the western region as an opportunity to focus the Government on seeking financial and policy support.

\subsection{Accurately grasp the profit, to intervene various types of information services in an orderly pattern}

For China's rural areas there is a wide range of information services model, from perfect platforms services, improve service efficiency point of view, mobile operators having the space to intervene in China's agricultural market information has not been fully formed, the Government Information Service in rural areas is still in a dominant position, mobile operators must accurately grasp each mode of information services which may link the earnings and 
profits in accordance with its ease which are involved in the development of the order of priority.

At present, agriculture-related government departments hold a wealth of agricultural information resources, the grass-roots level in rural China is the leading force in the information services, mobile operators should take advantage of its strengths information transmission, the priority to participate in government-led agricultural information services, for the country And local government funding and policy support for the Government to make full use of information resources, organizational systems and influence, and gradually expand its information services business, and through local governments for the provision of appropriate information service application platform to achieve profitability.

Secondly, mobile operators can be involved in agricultural products processing enterprises, agricultural enterprises and farm produce wholesale markets, such as the provision of information services for farmers among the models, to provide them with more convenient and efficient transmission platform to reduce the cost of information services to improve The effects of information through the supply and demand for the release of information companies must charge the cost of profits.

As the farmers association service model is peasant farmers self-service, and our farmers generally don't have high spending power on information, if mobile operators want to involve in the short-term model, which will be difficult to generate considerable economic benefits, if mobile operators can associate with peasant farmers to lead them to participate in the service mode, , for all aspects of operating profit, it is also necessary to seek other kinds of cooperation in a wide range of agriculture-related departments.

\section{REFERENCES}

Jierong Guo. 2007. Strategies of how to develop market in rural informatization by telecom companies. Communication World: 10: 24-25.

Jingyu Shi, Jianqiu Zeng. 2007. A discussion on the thought of mobile operators in rural informatization. Mobile Communications, 9: 91-94.

Qifeng Gu, Chengjie Yan. 2007. The opportunities of mobile operators in the rural informatization: to find a market in rural areas. Management of Communication Enterprise, 2: 48-49.

Yan Wang, Yufei Gao. 2006. Research on the Value Chain and Business Models for Mobile Commerce. Logistics Technology, 9: 63-66. 